\title{
The Comorbidity of PTSD and MDD: Implications for Clinical Practice and Future Research
}

\author{
Samantha Angelakis and Reginald D.V. Nixon \\ School of Psychology, Flinders University, Adelaide, South Australia, Australia
}

\begin{abstract}
The high prevalence of post-traumatic stress disorder (PTSD) and major depressive disorder (MDD) comorbidity is well established, with comorbidity rates often between 30 and $50 \%$. However, despite the high prevalence of this comorbidity, very few researchers have explored specific treatments for individuals who present with comorbid PTSD and MDD. Further, there has not been explicit examination of the mechanisms through which MDD influences trauma-focused therapy. As individuals with comorbid PTSD and MDD often present with a more chronic course of impairment and in some instances, a more delayed response to treatment, the need for such research is imperative. It will be proposed that there is merit in targeting depression within the treatment of comorbid PTSD and MDD. Accordingly, in this article we review explanations for the high PTSD and MDD comorbid relationship and highlight variables likely to explain such comorbidity. Theoretical accounts for how depression impedes optimal recovery from PTSD and the associated empirical findings are illustrated. We consequently argue that there is a need to develop and test treatments that target both PTSD and MDD symptoms. Directions for future research are highlighted.
\end{abstract}

Keywords: PTSD, MDD, comorbidity, treatment, emotional engagement

It is well established that post-traumatic stress disorder (PTSD) often co-occurs with depression. Over a range of sample and trauma types it has been observed that 30$50 \%$ of individuals with PTSD also meet the criteria for a diagnosis of depression (Creamer, Burgess, \& McFarlane, 2001; Kessler, Berglund et al., 2005). The high prevalence of PTSD and major depressive disorder (MDD) comorbidity is problematic as individuals with comorbid PTSD/MDD demonstrate a greater illness burden and lower levels of global functioning (Kessler, Chiu, Demler, \& Walters, 2005), a more chronic course of impairment (Post, Zoellner, Youngstorm, \& Feeny, 2011; Shalev et al., 1998), and a more delayed response to treatment (Green et al., 2006) than individuals with PTSD or MDD alone. Further, initial levels of depression have been associated with poorer treatment outcomes (Bryant, Moulds, Guthrie, Dang, \& Nixon, 2003; Taylor et al., 2001), although this is not always a consistent finding (Gillespie, Duffy, Hackmann, \& Clark, 2002). Despite such findings and irrespective of the high prevalence of PTSD/MDD comorbidity, few studies have tested treatments that address both PTSD and a comorbid condition, let alone PTSD and MDD explicitly. For example, while some research has begun to investigate this in

Address for correspondence: Dr Samantha Angelakis, School of Psychology, Flinders University, GPO Box 2100, Adelaide SA 5001, Australia.Email: samantha.angelakis@flinders.edu.au

Behaviour Change | Volume 32 | Number 1| 2015 | pp. 1-25 | (C) The Author(s) 2015

doi 10.1017/bec.2014.26 
relation to other PTSD comorbidities such as panic and substance use (Cloitre, Koenen, Cohen, \& Han, 2002; Najavits, Weiss, Shaw, \& Muenz, 1998), research has not examined the efficacy of using combined treatments to target comorbid PTSD/ MDD.

This article will review explanations for the high PTSD/MDD comorbid relationship. Next, likely candidate variables that would explain the high level of comorbidity between PTSD and MDD are reviewed, with a focus on a shared vulnerability account of the PTSD/MDD relationship. The article will then illustrate how depressive symptoms may impede optimal recovery from PTSD through review of both theoretical and empirical findings. Finally, it will be argued that there is merit in examining treatments that targets both PTSD and MDD symptoms.

\section{Pathways to Comorbid PTSD/MDD}

Research examining the temporal order of PTSD and MDD development has suggested several potential pathways to PTSD/MDD comorbidity. Some researchers have proposed that pre-existing MDD may elevate one's susceptibility to traumatic events (Breslau, Davis, Peterson, \& Schultz, 1997; Kessler, Sonnega, Bromet, \& Nelson, 1995). Others suggest that MDD may be a reaction to PTSD, whereby PTSD is a risk factor for the development of MDD (Breslau, Davis, Peterson, \& Schultz, 2000). Recently, Stander, Thomsen, and Highfill-McRoy (2014) examined the literature regarding the development of comorbid PTSD/MDD in military samples. Although the reviewed literature generally supported the hypothesis that PTSD was a causal risk factor for the development of MDD, they acknowledged that the exact relationship between PTSD and MDD was likely to be complex, involving bidirectional causality, common risk factors, and common vulnerabilities.

\section{Shared Vulnerability Pathway to Comorbid PTSD/MDD}

The finding that depression elevates the risk of developing PTSD after trauma exposure (Koenen et al., 2002) and the finding that PTSD increases the risk of developing first onset depression following a trauma (Breslau et al., 2000; Kessler et al., 1995) does suggest a bidirectional relationship between the two disorders and that this may occur due to a shared vulnerability or a shared diathesis. Methodologically sound prospective studies have shed light on the shared vulnerability relationship between PTSD and comorbid MDD. Breslau et al. (2000) explored PTSD-MDD pathways using retrospective and prospective data from a large sample of trauma victims $(N=$ 1,007), finding that those with pre-existing MDD were three times more likely to develop PTSD after trauma exposure compared with those without pre-existing depression. Further, relative to those who were not exposed to a trauma, those who were exposed to trauma and developed PTSD were 2.8 times more likely to develop MDD. However, those who were exposed to a trauma and did not develop PTSD were not significantly more likely to develop MDD. Using a similar prospective design with trauma victims recruited from a hospital emergency room, Shalev et al. (1998) found that the prevalence of MDD in patients with PTSD was $44 \%$ compared to $29 \%$ for those without PTSD. Cross-sectional studies further support the shared vulnerabilities explanation (see Brown, Campbell, Lehman, Grisham, \& Mancill, 2001; Nixon, Resick, \& Nishith, 2004). 
PTSD/MDD comorbidity is not an artifact of symptom overlap. The frequent comorbidity of PTSD and MDD has also been explained in terms of symptom overlap, with researchers positing that the disorders co-occur superficially due to the shared symptoms of sleep disturbances, diminished interest and involvement in everyday activities, and concentration difficulties. However, for the most part, this explanation has been discounted (e.g., Blanchard, Buckley, Hickling, \& Taylor, 1998; Ford, Elhai, Ruggiero, \& Frueh, 2009). Elhai, Grubaugh, Kashdan, and Frueh (2008) found that the lifetime prevalence rate of MDD among adults with PTSD (54.7\%) remained essentially the same when overlapping symptoms were removed and a prorated PTSD diagnostic algorism was applied (54.41\%). Further, using data taken from the National Survey of Adolescents, Ford et al. (2009) found that the rate of PTSD remained unchanged when overlapping symptoms were removed and an altered PTSD diagnostic algorithm was applied. Stander et al. (2014) also suggest that rather than PTSD and MDD comorbidity being the product of definitional confounds, common underlying dimensions for PTSD and MDD symptoms may actually be manifestations of common vulnerabilities.

However, alternative findings exist (e.g., Grubaugh, Long, Elhai, Frueh, \& Magruder, 2010). For instance, O'Donnell, Creamer, and Pattison (2004) explored the relationship between PTSD, MDD and comorbid PTSD/MDD in a sample of 363 injury survivors. They found that PTSD and MDD presented as independent constructs in the direct aftermath of a trauma. However at 1-year follow-up, PTSD and MDD symptoms no longer presented as unique constructs. While O'Donnell et al. found a merged traumatic stress response at 1 year, this is an exception to the majority of research.

The existence of a dysphoric factor within PTSD has also led researchers to posit that the elevated rate of PTSD/MDD comorbidity may occur superficially due to a shared, non-specific dysphoric factor. Nonetheless, the factor structure of PTSD still remains unclear, and contradictory findings exist. For instance, some researchers have demonstrated a shared underlying latent structure whereby PTSD and MDD symptoms are represented by a single, underlying structure (Elhai et al., 2011; Miller et al., 2010). Adding to this, others suggest that all PTSD symptoms are associated with general distress and that PTSD-specific symptoms are no less correlated with distress or depression than dysphoric symptoms (Elkit, Armour, \& Shevlin, 2010; Marshall, Schell, \& Miles, 2010). Alternatively, other researchers posit that PTSD and MDD are distinct factors and highlight distinguishable features within PTSD (Forbes et al., 2010; Post et al., 2011). For instance, longitudinal research has identified PTSD symptoms that uniquely account for later PTSD adjustment (i.e., hyperarousal) and suggest that such symptoms are different from those that predict both PTSD and MDD severity (Marshall, Schell, Glynn, \& Shetty, 2006; Schell, Marshall, \& Jaycox, 2004). There currently does not appear to be a clear pattern of methodological or sample differences that would account for such discrepancies.

Irrespective of the contradictory findings, and of most relevance to the current review, researchers have consistently demonstrated that PTSD and MDD remain distinct features when overlapping symptoms are removed. Further, as will be highlighted later, findings suggest that MDD influences treatment outcomes in those with PTSD. Thus, although PTSD and MDD may share a common dysphoric factor that influences comorbidity, PTSD and MDD as a whole appear to be separate constructs. Accordingly, there is still a critical need to further explore the relationship between PTSD and MDD and examine treatments for comorbid PTSD/MDD. 


\section{Possible Candidates to Explain Shared Vulnerability}

In line with a shared vulnerability pathway, numerous studies have indicated that risk factors for PTSD are also risk factors for MDD. For example, event severity, familial history of depression, childhood trauma, and pre-existing anxiety or depressive disorders are risk factors for PTSD and MDD (Bremmer, Southwick, Johnson, Yehuda, \& Charney, 1993; Breslau et al., 1997, 2000). Although it is acknowledged that these risk factors are not confined to PTSD and MDD and have been found in other psychopathologies (e.g., Kessler, Chiu et al., 2005), there are a number of other potential mechanisms shared by PTSD and MDD that may explain the high comorbidity of the disorders. These are now briefly reviewed.

Cognitive and memory processes. PTSD and MDD share similarities across numerous cognitive and memory processes. For instance, clients with MDD have been shown to experience intrusive memories at the same frequency and level of distress as those with PTSD (Brewin, Gregory, Lipton, \& Burgess, 2010). Further, it is well recognised that individuals with PTSD and MDD both demonstrate retrieval of overgeneralised autobiographical memories (Harvey, Bryant, \& Dang, 1998; Kuyken \& Dalgleish, 1995) and that such an overgeneralised retrieval style may develop as a way of regulating affect after a stressful event (Williams et al., 2007). Importantly, research demonstrates that overgeneralised memories are not simply a marker for psychopathology but can predict the onset and maintenance of PTSD and MDD (Kleim \& Ehlers, 2008). As overgeneralised memories may influence the onset and development of psychopathology, and as this has been demonstrated so reliably in PTSD and MDD (Williams et al., 2007), it is reasonable to posit that such common memory processes may explain why individuals are vulnerable to this comorbidity.

Shared cognitive vulnerabilities such as rumination may further drive PTSD/MDD comorbidity. Rumination is well established in PTSD and MDD (Michael, Halligan, Clark, \& Ehlers, 2007; Nolen-Hoeksema, 2000), with rumination surrounding the causes, consequences, and implications of a trauma, along with repetitive thinking about the causes and consequences of one's distress, found to predict PTSD and MDD symptom severity, onset, and maintenance (Ehlers, Mayou, \& Bryant, 1998; Ehring, Rank, \& Ehlers, 2008; Nolen-Hoeksema, 2000; Nolen-Hoeksema \& Morrow, 1991). Further, longitudinal studies have repeatedly found that post-trauma rumination predicts later PTSD and MDD (Michl, McLaughlin, Shepherd, \& Nolen-Hoeskema, 2013). Such a body of literature suggests that a tendency to ruminate may influence the development of MDD and anxiety (i.e., PTSD) following traumatic events, and suggests that a shared predisposition towards rumination may in part promote PTSD/MDD comorbidity.

Maladaptive cognitions are also critical in the etiology of PTSD and MDD. Depressive cognitions often relate to the self, the world, and the future and are characterised

4 by a sense of helplessness (Seligman, Abramson, Semmel, \& von Baeyer, 1979). Further, individuals with PTSD tend to interpret information in a way that leads to a sense of fear or persistent state of threat (Ehlers \& Clark, 2000). Unsurprisingly, the maladaptive cognitions inherent in PTSD and MDD overlap. Individuals with PTSD and MDD both show a tendency to interpret events in a negative manner, to catastrophise, and to blame themselves for events (Beck, Riskind, Brown, \& Steer, 1988; Dunmore, Clark, \& Ehlers, 2001). Additionally, individuals with PTSD often exhibit negative beliefs in line with Beck's cognitive triad. As maladaptive 
cognitions influence the onset and development of PTSD and MDD, and as maladaptive cognitions overlap in the two disorders, one may again posit that common, maladaptive cognitions further potentiate the comorbid PTSD/MDD relationship. The reviewed literature suggests that PTSD and MDD share a series of maladaptive cognitive and memory processes that may contribute to the high rate of PTSD/MDD comorbidity. Thus, comorbid PTSD/MDD can be viewed as the product of shared cognitive vulnerabilities. The review will now turn its attention to shared genetic factors.

Shared genetic influences in PTSD and MDD. Genetic influences explain a substantial proportion of the variance in PTSD and MDD. Twin studies of PTSD as well as MDD suggest that genetic influences explain approximately one third of the variance in PTSD and MDD onset (Sullivan, Neale, \& Kendler, 2000; True et al., 1993). Reviews examining candidate genes in PTSD have focused on the dopaminergic system (i.e., DRD2, DAT), the serotonin system (i.e., SLC6A4, 5-HTR2A), markers of the hypothalamic pituitary adrenal axis (i.e., GCCR, FKBP5, CNR1), and components of the locus coeruleus/noradrenergic system (i.e., NPY, DBH; Broekman, Olff, \& Boer, 2007; Cornelis, Nugent, Amstadter, \& Koenen, 2010), finding significant relations between these systems or genes and PTSD.

Given that PTSD and MDD are in part predicted by genetic influences, it is reasonable to suggest that comorbid PTSD/MDD may be explained by shared genetic factors. In line with this, researchers have explained PTSD/MDD comorbidity in terms of a shared diathesis of genetic origin (Koenen et al., 2008), with evidence so far being drawn from familiar risk research, twin studies, and more recently, identification of specific genes (Caspi et al., 2003; Fu et al., 2007; Kilpatrick et al., 2007; Lee et al., 2005). Such a body of literature suggests that there is significant commonality between the two disorders, with studies suggesting that genetic influences in PTSD are in line with those for MDD, and that most of the covariation between PTSD and MDD arises from genetic processes. For example, Fu et al. (2007) investigated the genetic etiology of PTSD and comorbid MDD in a sample of middle-aged male monozygotic and dizygotic twins from the Vietnam Era Twin Registry. They found that the association between PTSD and MDD was predominantly explained by genetic influences, whereby genetic influences explained 19\% of the variance in PTSD. Further, shared environmental factors did not account for significant covariance in MDD and PTSD.

However, no study to date has attempted to specifically differentiate those who develop PTSD or MDD alone after a trauma from those who develop comorbid PTSD/MDD. Further, while genetics may influence the development of comorbid PTSD/MDD, as PTSD develops in response to trauma (i.e., by definition requiring environmental influences for its development), external factors such as trauma severity may also have a determining role in the development of comorbidity. Thus, research must investigate whether gene-environment interactions are themselves moderated by these variables. As reviewed, PTSD/MDD comorbidity appears to occur due to the shared vulnerabilities of the disorders. As the interplay between the two disorders is likely to be complex, and as there has not been substantial empirical work on how to best treat comorbid PTSD/MDD, there is merit in considering how to best treat comorbid PTSD/MDD. This is now reviewed. 


\section{Justification for Targeting Depression in the Treatment of Comorbid PTSD/MDD}

Cognitive behavioural therapy (CBT) has been empirically supported as an effective treatment for PTSD and MDD (e.g., Butler, Chapman, Forman, \& Beck, 2006; Hollon, Shelton, \& Davis, 1993) and is recommended as the first-line treatment for PTSD (Australian Centre for Posttraumatic Mental Health, 2013; National Institute for Clinical Excellence [NICE], 2005) and MDD (NICE, 2009). However, not all clients benefit from CBT. For prolonged and imaginal exposure, non-response rates range from 25-60\%, and dropout rates between 0-50\% (Bradley, Greene, Russ, Dutra, \& Westen, 2005; Resick, Nishith, Weaver, Astin, \& Feuer, 2002; Schottenbauer, Glass, Arnkoff, Tendick, \& Gray, 2008). Given such response rates, there is a need to better understand factors associated with poorer treatment outcomes.

\section{The Influence of Depression on PTSD Treatment Outcomes}

While the evidence is not universal, several studies have demonstrated that MDD influences PTSD treatment outcomes (Taylor et al., 2001). In a sample of civilian survivors, Bryant et al. (2003) found that those who dropped out of CBT (including exposure) had higher levels of baseline depression than treatment completers. McDonagh et al. (2005) observed the same in a sample of childhood sexual abuse victims. Stein, Dickstein, Schuster, Litz, and Resick (2012) compared treatment response trajectories in participants allocated to cognitive processing therapy (CPT), CPT components, or prolonged exposure. Non-responders were more likely to have a diagnosis of MDD and report more severe baseline hyperarousal symptoms than nonresponders. They concluded that those with comorbid MDD may need additional treatment.

Although the above findings suggest that MDD inhibits treatment efficacy, this has not always been observed, with some studies finding MDD to be unrelated to treatment response or dropout (e.g., Aderka, Foa, Applebaum, Shafran, \& GilboaSchechman, 2011; Aderka, Gillihan, McLean, \& Foa, 2013; Ehlers et al., 1998). For example, Gillespie et al. (2002) found that comorbidity (including depression, alcohol abuse, and panic) was not associated with reduced treatment outcomes in PTSD sufferers. However, individuals with comorbid conditions received a greater number of treatment sessions. Further, Liverant, Suvak, Pineles, and Resick (2012) found that changes in PTSD and depressive symptoms during CPT and CPT treatment components occurred concurrently and that changes in one disorder did not influence changes in the other.

While it is tempting to conclude that one does not need to target MDD in the treatment of comorbid PTSD/MDD, the literature is in its infancy and ignores that in certain contexts MDD appears to impact outcome. Further, research to date has

6 primarily used mixed samples of individuals with PTSD only and individuals with comorbid PTSD/MDD, failing to analyse outcomes in terms of comorbidity. The use of such populations may partially account for contradictory findings and reduces our ability to determine if trauma-based treatments are sufficient when comorbidity is present. As not all individuals recover from PTSD, and as MDD may interfere with PTSD treatment outcome, there is a critical need to identify factors that affect treatment efficacy and explore the mechanisms through which MDD inhibits optimal recovery from PTSD. 


\section{Emotional Processing Theory: The Influence of Depression on PTSD Treatment}

In order to better understand how depression might influence PTSD outcomes, a brief description of emotional processing therapy is required (for a detailed description see Foa \& Kozak, 1986; and Foa, Huppert, \& Cahill, 2006). The theory posits that recovery from PTSD is a product of the degree to which one engages in emotional processing. Two processes are thought necessary for emotional processing. First, the fear structure must be activated and emotionally engaged with (Foa, Riggs, Massie, \& Yarczower, 1995; Jaycox, Foa, \& Morral, 1998); and second, information that is incompatible with elements in the fear structure needs to be incorporated to allow maladaptive elements to be replaced (Foa \& Cahill, 2001; Foa et al., 2006). Put simply, in order to recover from PTSD, or in order to achieve optimal treatment outcomes, emotional processing theory suggests that one must emotionally engage with traumarelated memories, thoughts and emotions in a manner that allows corrective learning to take place (Foa et al., 1995).

The theory makes specific suggestions for treatment and states that certain conditions promote the efficacy of trauma-based treatment. The theory proposes that for change to occur and treatment to be effective, a client must emotionally engage during treatment. However, the mere presence of engagement alone is not considered sufficient for positive outcomes. Rather, emotional processing theory emphasises that for treatment to be effective, an optimal level of engagement must be maintained, in which both too little (underengagement) and too much activation (overengagement) are posited to reduce treatment efficacy for PTSD (Rauch \& Foa, 2006).

Underengagement refers to when the fear structure is not sufficiently activated and relates to lower levels of emotional arousal. Overengagement occurs when the client's fear structure becomes overly activated during exposure. Overengagement is characterised by immense levels of distress that overwhelm one's ability to process information while recalling the trauma. Thus, within emotional processing theory treatment, outcomes are viewed to be a product of the degree to which a client successfully, or optimally, emotionally engages with trauma-related feelings, perceptions, memories and thoughts.

\section{Empirical Findings Related to Emotional Engagement and Treatment Outcomes}

Clinical research has repeatedly demonstrated the significant role emotional engagement plays in the acquisition of positive treatment outcomes in people with PTSD (Foa et al., 1995; Monson, Price, Rodriguez, Ripley, \& Warner, 2004). For instance, Jaycox et al. (1998) found that those who demonstrated high engagement (high arousal/distress) and high habituation were eight times more likely than those who demonstrated low engagement and low habituation to meet criteria for good posttreatment outcome.

The importance of emotional engagement extends to other psychopathologies, with a large body of literature consistently finding emotional processing and emotional engagement during MDD treatment to be critical to optimal treatment outcome (Goldman \& Greenberg, 2005; Greenberg, 2002a, 2002b; Missirlian, Toukmanian, Warwar, \& Greenberg, 2005; Pascual-Leone \& Greenberg, 2007; Poss, Greenberg, Goldman, \& Korman, 2003; Stringer, Levitt, Berman, \& Matthews, 2010). Further, 
research suggests that experiential avoidance or an unwillingness to experience feelings and thoughts is a core component of many disorders and is not restricted to PTSD (Beutler, Clarkin, \& Bongar, 2000; Greenberg \& Pascual-Leone, 2006; Hayes, Wilson, Gifford, Follette, \& Strosahl, 1996).

For example, Carryer and Greenberg (2010) demonstrated the complex relationship between emotional engagement and treatment outcomes in a sample of participants with depression being treated with experiential therapy. Expressed emotional arousal levels (independently coded from session tapes) were assessed during participants' three highest arousal sessions. Depressive symptom reduction was predicted by a non-linear pattern of expressed emotion in which optimal treatment gains were observed when clients experienced highly arousing emotions for $25 \%$ of their session. Deviations towards lower frequencies of high emotional arousal (i.e., underengagement) and deviations towards higher frequencies of high emotional arousal (i.e., overengagement) were associated with poorer treatment gains. Such findings indicate that the relationship between arousal and outcome is complex and that moderate levels of emotional arousal are required to produce positive therapeutic outcomes.

The reviewed literature suggests that emotional engagement is critical to treatment outcome and indicates that both too much and too little emotional engagement is associated with reduced treatment outcomes. This is in line with emotional processing theory's proposition that effective treatment requires an optimal level of engagement, and that under- and overengagement may predict reduced treatment efficacy. However, in spite of the reviewed literature, very few researchers have tested whether under- or overengagement directly influences treatment outcome. Further, most research is confined to the experiential treatment of MDD, with there being an absence of research looking into emotional engagement within the treatment of anxiety disorders and associated comorbid conditions.

As MDD is associated with emotion dysregulation, flattening of affect and cognitive difficulties, it would be reasonable to suggest that MDD may inhibit engagement during PTSD treatment. However, research is yet to test how MDD may influence emotional engagement and consequently treatment outcome. This will be explored in the following sections, with evidence suggesting that depressive features may influence treatment efficacy and reduce treatment outcomes in those with PTSD.

\section{How May Depressive Symptoms Inhibit Emotional Engagement and Treatment Outcomes?}

\section{Emotional Numbing}

Emotional numbing, a phenomenon inherent in the presentation of PTSD and MDD, reduces one's ability to experience and identify emotions, and can be characterised as a mechanism that inhibits emotional engagement during exposure 8 therapy (Jaycox \& Foa, 1996; Zimering, Caddell, Fairbank, \& Keane, 1993). Individuals with PTSD often report feeling cut off or numb from the world and their emotions (Feeny, Zoellner, Fitzgibbons, \& Foa, 2000). Similarly, individuals with moderate MDD experience low mood and anhedonia, while in severe cases of MDD there is a significant dulling of affect, which is often accompanied by severe psychomotor retardation (Lemke, Puhl, \& Winkler, 1999; Loas, Salinas, Guelfi, \& Samuel-Lajeunesse, 1992). Consequently, an inability to fully experience 
affect, as seen in MDD, may lead to underengagement during trauma-based treatment and potentially inhibit treatment outcomes in those with comorbid PTSD/ MDD.

Consistent with the notion that MDD-related emotional numbing may promote underengagement, research has found emotional numbing to influence PTSD and MDD treatment outcomes (Curry et al., 2006). For instance, McMakin et al. (2012) found that anhedonia predicted a longer and more severe course of MDD in a sample of young people receiving a new serotonin reuptake inhibitor or venlafazine, with or without CBT. They concluded that anhedonia was a robust predictor of time to remission and MDD-free days. Taylor et al. (2001) demonstrated that partial responders to PTSD-focused CBT tended to have higher levels of pretreatment numbing and depressive symptoms relative to full responders. Consistent with such findings, McMillen, North, and Smith (2000) suggest that trauma victims with considerable numbing symptoms might require different interventions from those with considerable reexperiencing and hyperarousal symptoms. They propose that interventions that explicitly address numbing symptoms, such as behavioural activation, might be of particular benefit to such individuals.

Related to emotional numbing, individuals with MDD often actively avoid negative emotional material (Kahn \& Garrison, 2009). Salters-Pednealt, Tull, and Roemer (2004) posit that emotional concealment reduces one's ability to engage with the environment, elevates distress, and inhibits the learning of non-threatening associations. Similarly, Baumeister, Bratslavsky, Muraven, and Tice (1998) and Richards and Gross (1999) suggest that any sort of self-regulation (i.e., concealment, suppression, avoidance) depletes mental resources, as attempts to control emotions during one task reduces resources needed to perform subsequent tasks. Specifically, Richard and Gross posit that successful emotion suppression may require an internal dialogue where one must constantly remind oneself to suppress and self-monitor outward signs of emotion, and conduct evaluations on how well one is doing. This dialogue may then consume finite attentional resources that would otherwise be used to process one's surroundings and events. Thus, emotional concealment or emotional numbing, as seen in MDD, may inhibit optimal treatment outcomes by interfering with cognitive processes that would otherwise be available for therapy.

A reduced ability to recognise emotions has also been found to predict heightened levels of psychopathology and poorer treatment outcomes (Rufer et al., 2004; Sloan \& Kring, 2007; Viinamäki et al., 2002). Thus, as individuals with MDD demonstrate reduced emotional awareness and difficulties expressing emotion (Suveg, SouthamGerow, Goodman, \& Kendall, 2007; Zeman, Klimes-Dougan, Cassano, \& Adrian, 2007), it is possible that such difficulties may again inhibit engagement and consequently reduce treatment outcomes in those with comorbid PTSD/MDD.

To review, emotional numbing and the concealment of emotion may potentially reduce treatment outcomes by: (1) reducing cognitive resources, (2) inhibiting one's ability to recall and utilise the information presented during therapy, (3) reducing one's ability to engage with their memories during therapy, and (4) reducing emotional awareness. Thus, emotion concealment and a general difficulty experiencing and identifying emotions, as seen in MDD where numbing is a component of the depressive presentation, is likely to contribute to underengagement during PTSD treatment and reduce outcomes. However, as current research is limited, further empirical work is required to test these proposals. 


\section{Depression and Emotion Regulation}

Emotion regulation is critical in the initiation and organisation of adaptive behaviours and reduces the likelihood of experiencing stressful levels of unpleasant emotions (Garnefski et al., 2002). Emotion dysregulation is associated with ruminative responses to distress, poor emotional awareness, and dysregulated anger and sadness expression across disorders (Aldao, Nolen-Hoeksema, \& Schweizer, 2010). Individuals with MDD exhibit difficulties regulating their emotions and utilise more maladaptive emotion regulation strategies than non-depressed individuals (Garnefski, Kraaij, \& Spinhoven, 2001; Gotlib \& Joormann, 2010). More precisely, the dysfunctional attention, memory, and interpretation processes associated with MDD have been found to promote the use of maladaptive emotion regulation strategies and reduce the use of more adaptive strategies (Joormann \& D'Avanzato, 2010). As adaptive emotion regulation reduces stressful levels of emotions (i.e., under- and overengagement), and because individuals with MDD experience a reduced ability to regulate emotion, it is possible that MDD interferes with engagement during PTSD treatment. Specifically, reduced emotional regulation may make individuals with MDD more prone to under- or overengagement during PTSD treatment and therefore reduce outcomes for those with comorbid PTSD/MDD. This proposal is speculative as no study to date has examined how emotion dysregulation impacts engagement during PTSD treatment. Despite this, as discussed next, the specific types of emotion regulation strategies people with MDD use may shed light on the likely mechanisms through which this could influence the emotional processing of traumatic material.

Individuals with MDD use maladaptive emotion regulation strategies such as avoidance and suppression (Garnefski et al., 2002; Nolen-Hoeksema, 2000). As an example, although suppression alleviates the expression and possibly the experience of negative emotions in the short term, it also contributes to the maintenance of emotional and physiological distress. Analog and clinical research has demonstrated that suppression can lead to hypersensitivity and increased accessibility to unwanted material, and concomitant emotional and physiological arousal (Nixon, Cain, Nehmy, \& Seymour, 2009; Wenzlaff \& Wegner, 2000). Therefore, in PTSD sufferers with MDD, such suppression may promote overengagement with the trauma memory and prevent the incorporation of new information into the fear structure. However, it may also be the case that individuals with MDD suppress so well that they exhibit underengagement by failing to emotionally engage with the trauma memory. Research is yet to test these hypotheses.

An effective way to regulate emotion is to redirect attention away from emotioneliciting stimuli (Gotlib \& Joormann, 2010). However, attention and eye-gaze studies demonstrate that individuals with MDD have difficulties disengaging from negative material (Caseras, Garner, Bradley, \& Mogg, 2007) and show biases towards depression-relevant stimuli such as socially threatening or depression-related words (Bradley, Mogg, \& Lee, 1997; Broomfield, Davies, MacMahon, Ali, \& Cross, 2007;

10 Nunn, Mathews, \& Trower, 1997). This is problematic, as maintained attention on such negative material may maintain dysphoric mood in individuals with MDD as it enhances their tendency to mull over negative information, increases reactivity to that information, and elevates distress (Joormann \& Gotlib, 2010). Along similar lines, Brewin and colleagues (Brewin, Hunter, Carroll, \& Tata, 1996; Brewin et al., 2010), drawing on work from the depression field (e.g., Dalgleish \& Watts, 1990), proposed that MDD in the context of PTSD enhances access to negative memories and 
reduces access to positive memories. This greater accessibility of negative memories further potentiates MDD, leading to a vicious cycle. Brewin et al. (1996) suggest that MDD may prolong unhelpful emotional processing (i.e., increased focus on negative material) and result in more chronic PTSD. Therefore, the tendency individuals with MDD have to dwell on negative information, or more explicitly, their difficulty disengaging from negative material, may cause them to become preoccupied with negative content during therapy. This may consequently reduce attention to positive material and contribute to overengagement during PTSD treatment. Of course, it may not necessarily be the accessibility of negative memories that further potentiates MDD, but rather the distress associated with such negative memories. In summary, problems disengaging from negative material and elevated levels of suppression and avoidance may frustrate emotional engagement in people with MDD and inhibit the optimal treatment of comorbid PTSD/MDD.

\section{Depression and Maladaptive Cognitive Processes}

Depression is associated with a range of maladaptive cognitive processes, including persuasive negative appraisals and ruminative response styles (Haaga, Dyck, \& Ernst, 1991). Such processes not only influence the onset and maintenance of MDD (NolenHoeksema, 2000) but also influence treatment outcomes (Beevers, Wells, \& Miller, 2007). Although the literature is scarce, research is also beginning to indicate that individuals with comorbid PTSD/MDD possess stronger negative cognitions than those with PTSD or MDD alone (Menne, 2005; Nixon et al., 2004). Relatedly, and using a cross-sectional design, Gonzalo, Kleim, Donaldson, Moorey, and Ehlers (2012) examined attributional styles and post-trauma cognitions and found depressive attributions and post-trauma negative beliefs to independently predict MDD and PTSD severity. Further, those with PTSD alone endorsed fewer depressive attributions than those with comorbid PTSD/MDD or MDD. As MDD is associated with maladaptive cognitions, and as research implicates negative cognitions as inhibiting good treatment outcomes in MDD and PTSD (Hamilton \& Dobson, 2002), one would expect that the negative cognitions associated with MDD could impede recovery from comorbid PTSD/MDD. For instance, depressive cognitions may have an additive effect that enhances the potency of negative, trauma-related cognitions that subsequently increases the difficulty of altering these unhelpful beliefs. Foa and Kozak (1986) further outline how negative cognitions may reduce emotional engagement and treatment outcomes. They suggest that for individuals with MDD, maladaptive beliefs such as self-perceptions of ineffectiveness or helplessness may facilitate learning deficits (i.e., a reduced ability to incorporate corrective information within one's fear structure). Further, the tendency in MDD to attribute success to external sources and failure to internal causes may reduce self-efficacy regarding one's ability to cope with stress and strong emotion. This may consequently promote underengagement in traumafocused therapy as an individual with MDD may believe that they cannot handle their emotions and must therefore inhibit their emotional expression. However, research is again yet to clarify whether this is the case.

As noted, depressive rumination (sometimes labelled 'abstract' rumination) may also influence treatment outcomes in those with comorbid PTSD/MDD. Some models of depression conceptualise rumination as a problematic escape behaviour that is not dissimilar to overt forms of avoidance (Martell, Addis, \& Jacobson, 2001). The behavioural activation model explicitly acknowledges the role of rumination, and 
while it suggests that rumination is distinct from other more obvious forms of avoidance (e.g., social withdrawal), it posits that the function is the same. That is, that rumination operates to actively avoid engagement with the environment. In line with such a conceptualisation, Moulds, Kandris, Starr, and Wong (2007) found rumination, avoidance and depression to be significantly correlated in a non-clinical sample. Further, rumination and behavioural avoidance remained related when anxiety was controlled. By conceptualising rumination as an active form of avoidance, rumination is likely to inhibit the processing and elicitation of trauma memories and emotions, and depressed individuals with a ruminative response style are likely to underengage during PTSD treatment and show poorer outcomes.

Others, however, conceptualise rumination differently, suggesting that its effects extend beyond being a form of avoidance. It is well established that individuals with MDD exhibit cognitive deficits such as impaired memory and problems with attention set shifting (Levens, Muhtadie, \& Gotlib, 2009; Paelecke-Habermann, Pohl, $\&$ Leplow, 2005). Recent findings also indicate that rumination further captures cognitive resources, thereby preventing these resources from being used in other effortful tasks (e.g., Levens et al.). That is, when faced with complex tasks, individuals with MDD find it hard to stop ruminating and to instead organise cognitive resources to maximise their performance. If MDD is associated with a reduced ability to manage cognitive resources, and if rumination indeed drains cognitive resources, depressive rumination may inhibit emotional engagement during therapy as the individual has fewer cognitive resources available to engage with the trauma memory.

Finally, Smith and Alloy (2009) provide yet another explanation as to how rumination impedes treatment outcome. Smith and Alloy suggest that depressive rumination inhibits one's ability to adaptively and fully experience negative emotions. From this perspective, depressive rumination may again inhibit one's ability to fully experience trauma-related emotions and memories, consequently facilitating underengagement and reducing treatment outcomes during the treatment of comorbid PTSD/MDD. The literature suggests that depressive rumination may inhibit engagement with the trauma memory, as rumination reduces one's ability to adaptively experience negative emotions, reduces the availability and allocation of cognitive resources, and is akin to a form of avoidance. This would therefore impede outcomes in those with comorbid PTSD/MDD. However, as depressive rumination has not been explicitly examined as a barrier to engagement, such predictions require exploration.

\section{Depression and Overgeneralised Memories}

As stated earlier, people with MDD exhibit problems in the retrieval of specific memories and have a tendency to retrieve overgeneralised memories (Williams et al., 2007; Williams \& Scott, 1988). Although not yet studied in samples of individuals with comorbid PTSD/MDD, studies of separate samples of PTSD and MDD sufferers

12 have shown overgeneralised memory to be associated with the onset and maintenance of PTSD (Kleim \& Ehlers, 2008) and MDD (Summer, Griffith, \& Mineka, 2010) and to reduce treatment outcome (Brittlebank, Scott, Williams, \& Ferrier, 1993; Harvey et al., 1998). For example, Dalgleish, Spinks, Yiend, and Kuyken (2001) found that the extent to which individuals retrieved overgeneral memories predicted delayed recovery from affective disorders.

The retrieval of overgeneralised memories may in part reflect a form of functional avoidance whereby the retrieval of general memories reduces the distress that the 
retrieval of specific memories would usually elicit. Dalgleish, Rolfe, Golden, Dunn, and Barnard (2008) asked participants to complete a standard autobiographical memory test (AMT) and a reversed AMT (i.e., provide general memories rather than specific) and found that distress was associated with reduced recall specificity. Similarly, Boritz, Angus, Monette, Hollis-Walker, and Warwar (2011) found that the retrieval of more specific autobiographical memories during treatment for MDD was positively associated with peak emotional arousal. This suggests that retrieval of specific memories requires the evocation of visual and experiential imagery that consequently evokes deeper emotional arousal. They concluded that individuals with MDD may retrieve memories in a more general manner to avoid deeper emotional experiences and that this may consequently inhibit levels of engagement during therapy. While this avoidance may be another type of maladaptive emotion regulation strategy discussed earlier, it is also possible that the underlying processing that leads to this retrieval style has implications for how trauma memories are retrieved and the level of engagement exhibited by a suffer with comorbid PTSD/MDD during this processing. More explicitly, this retrieval style may hinder processing and reduce engagement (i.e., underengagement) during PTSD treatment.

The contribution of impaired executive ability to autobiographical memory deficits has also been highlighted (see Dalgleish et al., 2008). From this perspective, reduced executive control (i.e., reduced planning and monitoring abilities) and the subsequent creation of overgeneralised autobiographical memory may reduce the ability individuals with MDD have to incorporate corrective information into their fear structures, subsequently influencing treatment success. Overall, depression-related overgeneralised memories and reduced executive control may promote underengagement and reduce one's ability to incorporate corrective information during PTSD treatment, consequently hindering outcomes.

\section{Summary}

As reviewed, depressive symptoms may hinder optimal engagement during traumafocused therapy and consequently reduce treatment outcomes in those with comorbid PTSD/MDD. As such, the practice of treating PTSD alone may not be the most effective means of treating comorbid PTSD/MDD as it may not address the mutual relationship between the two disorders, nor the detrimental effects that depressive symptoms may have on treatment outcomes. Thus, the combined treatment of both disorders may be more effective for this patient group. The following section will now review potential treatment pathways for comorbid PTSD/MDD.

\section{Potential Treatment Pathways for Comorbid PTSD/MDD}

The reviewed literature suggests that a closer examination of the role of MDD symptoms on PTSD therapy outcomes is warranted. Given the high prevalence of PTSD and MDD comorbidity, it is somewhat surprising that intervention research to target the two is lacking, especially considering adjunctive therapies for other PTSD comorbidities such as panic and substance abuse have been examined (Falsetti, Resnick, \& Davis, 2005; Najavits et al., 1998). The one study to date that has explicitly examined treating comorbid PTSD/MDD is described, and potential ways of treating this comorbidity highlighted.

Nixon and Nearmy (2011) tested a combined treatment program for individuals with comorbid PTSD/MDD $(n=20)$. Individuals underwent six sessions of 
behavioural activation (BA) therapy for MDD followed by up to ten sessions of trauma-focused therapy. They found a decrease in PTSD $(d=0.47)$ and MDD $(d$ $=0.36)$ severity between pre- and midtreatment, and a decrease in PTSD symptoms $(d=0.81)$ from mid- to post-treatment. Symptom reduction was maintained at 3month follow-up ( $d=1.49$ and 0.75 , for PTSD and MDD respectively). Such findings point to the utility of using BA in the treatment of comorbid PTSD/MDD.

Other researchers have explored the value of using BA as a stand-alone treatment of PTSD (Jakupcak, Wagner, Paulson, Varra, \& McFall, 2010; Wagner, Zatzick, Ghesquiere, \& Jurkovich, 2007). As PTSD and MDD are both in part maintained by withdrawal and avoidance (Ehlers \& Clark, 2000; Martell et al., 2001), researchers have justified using BA for the treatment of PTSD as BA aims to reverse such patterns of avoidance and is similar to invivo exposure typically used for PTSD. However, smallscale pilot and treatment studies have found BA to only have small to moderate effects on PTSD symptoms, and often PTSD symptoms still remain within the moderate to severe range at post-treatment (Jackupcak et al., 2006; Mulick \& Naugle, 2004). Interestingly, BA for PTSD has also been found to only have limited effects on MDD symptoms, with studies failing to find significant reductions on self-reported depression scores at post-treatment and follow-up (Wagner et al., 2007) and some studies even reporting increases, albeit non-significant, in depression severity (Jakupcak et al., 2006).

While comorbidity in PTSD is widespread, there is no clear clinical consensus based on empirical grounds as to whether one should treat the other disorder when it co-occurs with PTSD. The treatment of comorbid PTSD/MDD can be approached in a variety of ways. One could simply treat PTSD for as a long as needed to also resolve MDD. Or, as MDD is proposed to inhibit optimal treatment outcomes, one could develop a combined treatment that targets both PTSD and MDD symptoms. Such treatment avenues are now discussed.

\section{Trauma Focused Therapy for Comorbid PTSD/MDD}

The effects of trauma-focused CBT are not confined to PTSD symptoms, with traumafocused therapy consistently producing significant reductions in depressive symptoms (Foa et al., 1999; Resick \& Schnicke, 1992; Resick, et al., 2008; Resick et al., 2002). For instance, Resick et al. (2008) found that at pretreatment, 51\% of treatment completers had an MDD diagnosis, whereas $16 \%$ continued to meet the diagnosis at post-treatment and only $13 \%$ at the 6-month follow-up. However, the question still remains as to whether a single focus on PTSD is the most effective means of treating comorbid PTSD/MDD. Although no study to date has explored whether a single focus on PTSD is superior to a treatment program that also focuses on MDD, this has been examined in non-PTSD comorbidities (Schulte, Künzel, Pepping, \& Schulte-Bahrenberg, 1992), and findings suggest that treatments focused on principal diagnoses may reduce comorbidity severity.

For example, Craske et al. (2007) allocated participants with panic disorder and another comorbid anxiety or mood disorders $(n=65)$ to either CBT that focused solely on the panic disorder, or CBT that focused on the panic disorder and the most severe comorbid condition. Both treatments led to reductions in panic symptoms $(E S=0.72)$ and a decline in the severity $(E S=0.63)$ and number of comorbid disorders $(E S=0.42)$. Further, panic disorder-focused CBT produced greater improvements in the most severe baseline comorbid condition $(E S=0.11)$. Similarly, dismantling 
studies of treatment for PTSD suggest that additional therapeutic components may not always translate to better treatment outcomes (Foa et al., 1999; Foa et al., 2005). However, it should be noted that studies exploring the utility of a single treatment focus on comorbidity often report small effect sizes, with some studies failing to demonstrate maintained treatment superiority at follow-up. Additionally, such studies have included mixed samples of PTSD and comorbid PTSD/MDD sufferers and have not separately examined outcomes.

Trauma-focused therapy may have positive effects on comorbidity for numerous reasons. For instance, individuals may apply core CBT strategies to comorbid symptoms, or such treatments may target and improve emotion processes that are shared across emotional disorders (i.e., negative affectivity, perceived lack of emotional control). Further, trauma-focused CBT may be effective in reducing MDD symptoms as the treatment shares much in common with typical MDD treatments. For instance, CPT and cognitive therapy (the latter used to treat MDD) both target maladaptive cognitions.

Evidence supporting the efficacy of trauma-focused therapy in reducing comorbid symptoms at face value suggests that PTSD treatment alone may be sufficient to treat comorbid PTSD/MDD. However, such a proposition is tentative as research to date has not explored if a single focused PTSD treatment is superior to a treatment program that focuses both on PTSD and MDD. Further, as the above findings primarily relate to mixed samples of individuals with PTSD alone and those with comorbid PTSD/MDD, results may not extend to samples that consist entirely of individuals with comorbid PTSD/MDD. It may be the case that when depression is elevated (as is the case in comorbidity), trauma-focused therapy alone is not sufficient to reduce such symptoms.

\section{Combined Treatments for PTSD When Comorbidity is Present}

Research has also explored the efficacy of using a combined treatment approach, whereby a focus is placed on treating both PTSD and the comorbid condition in either an integrated or sequential manner. While research has rarely explicitly targeted MDD in the treatment of comorbid PTSD/MDD, research has examined the comorbid relationship between PTSD and disorders other than MDD, such as panic and substance abuse (Cloitre et al., 2002; Najavits et al., 1998). Current literature surrounding the combined treatment of PTSD and another comorbid condition suggests that combined treatments lead to significant reductions in PTSD and comorbid symptoms and suggest that there may be utility in targeting both PTSD and the comorbid condition (Cloitre et al., 2002; Desai, Harpaz-Rotem, Najavits, \& Rosenheck, 2008; Falsetti et al., 2005; Najavits, Harpaz-Rotem, Najavits, \& Rosenheck, 2006; Najavits et al., 1998; Wald, Taylor, Chiri, \& Sica, 2010). Further, some studies suggest that by treating the comorbid condition initially, trauma-focused therapy may be made more tolerable for clients (Cloitre et al.; Cook, Walser, Kane, Ruzek, \& Woddy, 2006; Falsetti et al., 2005).

However, it should be noted that some studies have failed to illustrate the effectiveness of combined treatment (e.g., Hein, Cohen, Miele, Litt, \& Capstick, 2004; Hein, Wells, \& Nunes, 2009, in the context of substance disorders) and methodological issues are apparent. Current examinations of combined treatments for PTSD and comorbid conditions tend to compare combined treatments to no-treatment controls, and there is a near absence of studies that compare combined treatments to 
single-focused treatments that target PTSD alone. Further, sample sizes remain relatively small, consequently reducing statistical power and generalisability. As such, we are currently unable to determine if combined treatments that target PTSD and comorbidity produce superior outcomes compared to single treatments that focus on PTSD alone.

While combined treatments may be used to target comorbid conditions, there has been a surge of research examining unified treatment protocols that target a variety of unipolar mood and anxiety disorders simultaneously (e.g., Erickson, Janeck, \& Tallman, 2007; Moses \& Barlow, 2006; Norton \& Philipp, 2008). Thus, it may not necessarily be that a combined or sequential treatment approach is required in the treatment of comorbid PTSD/MDD, but that a unified treatment that targets common underlying factors and deficits inherent within this presentation is sufficient. However, there is currently contention surrounding the usefulness of transdiagnostic treatments (Mansell, Carey, \& Tai, 2013), and although transdiagnostic treatments have been found to be effective for eating disorders and emotional disorders, no study to date has explored the effectiveness of a transdiagnostic approach for PTSD when comorbidity is present. Further, transdiagnostic treatments are seldom compared to single-diagnosis treatments.

In sum, although some studies suggest that a single focus on PTSD is sufficient to treat PTSD when comorbidity is present, other studies highlight the merit of using combined or sequential treatments that target both PTSD and the comorbid disorder. As single focused PTSD treatments have not been consistently compared to sequential or combined treatments, we are not currently in a position to unequivocally determine the best means of treating PTSD when comorbidity exists, and whether a single versus combined treatment approach is preferred. As MDD symptoms may interfere with treatment outcomes, at a conceptual level, a combined treatment approach appears beneficial. In line with the reviewed research, it would not be misguided to propose that if MDD was addressed prior to PTSD treatment, the negative effect depressive symptoms have on engagement could be minimised and PTSD treatment outcomes enhanced. However, given the paucity of research on this issue, this idea remains speculative.

\section{Future Research and Conclusion}

This review has highlighted several critical areas in relation to comorbid PTSD/MDD. First, an argument was put forward that PTSD/MDD comorbidity may be the product of shared vulnerabilities. Second, within an emotional processing framework, the barriers to treatment outcomes were identified, with specific discussion of the processes through which depression may inhibit optimal levels of emotional engagement. Finally, avenues of treating comorbid PTSD/MDD were noted and the merit of a combined treatment approach noted.

16 A number of important research avenues have been suggested. Experimental work should determine whether MDD impedes emotional engagement and if so, the exact mechanisms through which MDD inhibits treatment outcomes. While theory and clinical observations support the proposition that MDD impedes treatment outcomes, systematic investigation is lacking. Future research should also test varying treatment approaches (sequential, combined) for comorbid PTSD/MDD. Researchers should examine whether for those with comorbid PTSD/MDD, combined treatments and cross-over designs should also be used to explore if the order in which treatment 
approaches are conducted impacts outcomes. A better understanding of these processes would benefit those with comorbid PTSD/MDD and contribute to our understanding of the complex relationship between PTSD and MDD.

\section{References}

Aderka, I.M., Foa, E.B., Applebaum, E., Shafran, N., \& Gilboa-Schechman, E. (2011). Direction of influence between posttraumatic and depressive symptoms during prolonged exposure therapy among children and adolescents. Journal of Consulting and Clinical Psychology, 79, 421-425. doi: $10.1037 / \mathrm{a} 0023318$

Aderka, I.M., Gillihan, S.J., McLean, C.P., \& Foa, E.B. (2013). The relationship between posttraumatic and depressive symptoms during prolonged exposure with and without cognitive restructuring for the treatment of posttraumatic stress disorder. Journal of Consulting and Clinical Psychology, 81, 375-382. doi:10.1037/a0031523

Aldao, A., Nolen-Hoeksema, S., \& Schweizer, S. (2010). Emotion-regulation strategies across psychopathology: A meta-analytic review. Clinical Psychology Review, 30, 217-237. doi:10.1016/j.cpr.2009.11.004

Australian Centre for Posttraumatic Mental Health. (2013). Australian guidelines for the treatment of acute stress disorder and posttraumatic stress disorder. Melbourne, Australia: Author.

Baumeister, R.F., Bratslavsky, E., Mark, M., \& Tice, D.M. (1998). Ego depletion: Is the active self a limited resource? Journal of Personality and Social Psychology, 74, 1252-1265. doi:10.1037/0022-3514.74.5.1252

Beck, A.T., Riskind, J.J., Brown, G., \& Steer, R.A. (1988). Levels of hopelessness in DSM-III disorders: A partial test of content specificity in depression. Cognitive Therapy and Research, 12, 459-469. doi:10.1007/BG011734313

Beevers, C.G., Wells, T.T., \& Miller, I.W. (2007). Predicting response to depression treatment: The role of negative cognition. Journal of Consulting and Clinical Psychology, 75, 422-431. doi: $10.1037 / 0022-006 X .75 .3 .422$

Beutler, L.E., Clarkin, J.F., \& Bongar, B. (2000). Guidelines for the systematic treatment of the depressed patient. York, England: Oxford University Press.

Blanchard, E.B., Buckley, T.C., Hickling, E.J., \& Taylor, A.E. (1998). Posttraumatic stress disorder and comorbid major depression: Is the correlation an illusion. Journal of Anxiety Disorders, 12, 2-37. doi:10.1016/S0887-6185(97)00047-9

Boritz, T.Z., Angus, L., Monette, G., Hollis-Walker, L., \& Warwar, S. (2011). Narrative and emotion integration in psychotherapy: Investigating the relationship between autobiographical memory specificity and expressed emotional arousal in brief emotion-focused and client-centred treatments of depression. Psychotherapy Research, 21, 16-26. doi:10.1080/10503307.2010.504240

Bradley, B.P., Mogg, K., \& Lee, S.C. (1997). Attentional biases for negative information in induced and naturally occurring dysphoria. Behaviour Research and Therapy, 35, 911-927. doi:10.1016/S0005-7967(97)00053-3

Bradley, R., Greene, J., Russ, E., Dutra, L., \& Western, D. (2005). A multidimensional meta-analysis of psychotherapy for PTSD. American Journal of Psychiatry, 162, 214-227. doi:10.1176/appi.ajp.162.2.214

Bremmer, J.D., Southwick, S.M., Johnson, D.R., Yehuda, R., \& Charney, D.S. (1993). Childhood physical abuse and combat-related posttraumatic stress disorder in Vietnam veterans. American Journal of Psychiatry, 150, 235-239.

Breslau, N., Davis, G.C., Peterson, E.L., \& Schultz, L. (1997). Psychiatric sequelae of posttraumatic stress disorder in women. Archives of General Psychiatry, 54, 81-87. doi:10.1001/archpsyc.1997.01830130087016

Breslau, N., Davis, G.C., Peterson, E.L., \& Schultz, L.R. (2000). A second look at comorbidity in victims of trauma: The posttraumatic stress disorder-major depression connection. Biological Psychiatry, 48, 902-909. doi:10.1016/S0006-3223(00)00933-1 
Brewin, C.R., Gregory, J.D., Lipton, M., \& Burgess, N. (2010). Intrusive images in psychological disorders: Characteristics, neural mechanisms, and treatment implications. Psychological Review, 117, 210-232. doi:10.1037/a0018113

Brewin, C.R., Hunter, E., Carroll, F., \& Tata, P. (1996). Intrusive memories in depression: An index of schema activation. Psychological Medicine, 26, 1271-1276. doi:10.1017/S0033291700035996

Brittlebank, A.D., Scott, J., Williams, J.M., \& Ferrier, I.N. (1993). Autobiographical memory in depression: State or trait marker? The British Journal of Psychiatry, 162, 118-121. doi:10.1192/bjp.162.1.118

Broekman, B.F.P., Olff, M., \& Boer, F. (2007). The genetic background to PTSD. Neuroscience and Biobehavioral Reviews, 31, 348-362. doi:10.1016/j.neubiorev.2006.10.001

Broomfield, N.M., Davies, R., MacMahon, K., Ali, F., \& Cross, S.M.B. (2007). Further evidence of attention bias for negative information in late life depression. International Journal of Geriatric Psychiatry, 22, 175-180. doi:10.1002/gps.1655

Brown, T.A., Campbell, L.A., Lehman, C.L., Grisham, J.R., \& Mancill, R.B. (2001). Current and lifetime comorbidity of the DSM-IV anxiety and mood disorders in a large clinical sample. Journal of Abnormal Psychology, 110, 585-599. doi:10.1037/0021-843X.110.4.585

Bryant, R.A., Moulds, M.L., Guthrie, R.M., Dang, S.T., \& Nixon, R.D.V. (2003). Imaginal exposure alone and imaginal exposure with cognitive restructuring in treatment of posttraumatic stress disorder. Journal of Consulting and Clinical Psychology, 71, 706-712. doi:10.1037/0022-006X.71.4.706

Butler, A.C., Chapman, J.E., Forman, E.M., \& Beck, A.T. (2006). The empirical status of cognitive-behavioural therapy: A review of meta-analyses. Clinicial Psychology Review, 26, 17-31. doi:10.1016/j.cpr.2005.07.003

Butler, L.D., \& Nolen-Hoeksema, S. (1994). Gender differences in response to depressed mood in a college sample. Sex Roles, 30, 331-346. doi:10.1007/BF01420597

Carryer, J.R., \& Greenberg, L.S. (2010). Optimal levels of emotional arousal in experiential therapy of depression. Journal of Consulting and Clinical Psychology, 78, 190-199. doi:10.1037/a0018401

Caseras, X., Garner, M., Bradley, B.P., \& Mogg, K. (2007). Biases in visual orienting to negative and positive scenes in dysphoria: An eye movement study. Journal of Abnormal Psychology, 116, 491-497. doi:10.1037/0021-843X.116.3.491

Caspi, A., Sugden, K., Moffitt, T.E., Taylor, A., Craig, I.W., Harrington, H., . . Poulton, R. (2003). Influence of life stress on depression: Moderation by a polymorphism in the 5-HTT gene. Science, 301, 386-389. doi:10.1126/science. 1083968

Cloitre, M., Koenen, K.C., Cohen, L.C., \& Han, H. (2002). Skills training in affective and interpersonal regulation followed by exposure: A phase based treatment for PTSD related to childhood abuse. Journal of Consulting and Clinical Psychology, 70, 1067-1074. doi:10.1037//0022-006X.70.5.1067

Cook, J.M., Walser, R.D., Kane, V., Ruzek, J.I., \& Woddy, G. (2006). Dissemination and feasibility of a cognitive-behavioral treatment for substance use disorders and posttraumatic stress disorder in the veterans administration. Journal of Psychoactive Drugs, 38, 89-92. doi:10.1080/02791072.2006.10399831

Cornelis, M.C., Nugent, N.R., Amstadter, A.B., \& Koenen, K.C. (2010). Genetics of post-traumatic stress disorder: Review and recommendations for genome-wide association studies. Current Psychiatry Reports, 12, 313-326. doi:10.1007/s11920-010-0126-6

Craske, M.G., Farchione, T.J., Allen, L.B., Barrios, V., Stoyanova, M., \& Rose, R. (2007). Cognitive behavioral therapy for panic disorder and comorbidity: More of the same or less of more? Behaviour Research and Therapy, 45, 1095-1109. doi:10.1016/j.brat.2006.09.006

Creamer, M., Burgess, P., \& McFarlane, A. (2001). Post-traumatic stress disorder: Findings from the Australian National Survey of Mental Health and Well-Being. Psychological Medicine, 31, 1237-1247. doi:10.1017/S0033291701004287

Curry, J., Rohde, P., Simona, A., Silva, S., Vitiello, B., Kratochvil, C., ... March, J. (2006). Predictors and moderators of acute outcome in the treatment for adolescents with depression study (TADS). Journal of American Academy of Child and Adolescent Psychiatry, 45, 1427-1439. doi:10.1097/01.chi.0000240838.78984.e2 
Dalgleish, T., Rolfe, J., Golden, A., Dunn, B.D., \& Barnard, P.J. (2008). Reduced autobiographical memory specificity and posttraumatic stress: Exploring the contributions of impaired executive control and affect regulation. Journal of Abnormal Psychology, 117, 236-241. doi:10.1037/0021-843X.117.1.236

Dalgleish, T., Spinks, H., Yiend, J., \& Kuyken, W. (2001). Autobiographical memory style in seasonal affective disorder and its relationship to future symptom remission. Journal of Abnormal Psychology, 110, 335-340. doi:10.1037/0021-843X.110.2.335

Dalgleish, T., \& Watts, F.N. (1990). Biases of attention and memory in disorders of anxiety and depression. Clinical Psychology Review, 10, 589-604. doi:10.1016/0272-7358(90)90098-U

Desai, R.A., Harpaz-Rotem, I., Najavits, L.M., \& Rosenheck, R.A. (2008). Impact of the Seeking Safety Program on clinical outcomes among homeless female veterans with psychiatric disorders. Psychiatric Services, 59, 996-1003. doi:10.1176/appi.ps.59.9.996

Dunmore, E., Clark, D.M., \& Ehlers, A. (2001). A prospective investigation of the role of cognitive factors in persistent posttraumatic stress disorder (PTSD) after physical or sexual assault. Behaviour Research and Therapy, 39, 1063-1084. doi:10.1016/S0005-7967(00)00088-7

Ehlers, A., \& Clark, D.M. (2000). A cognitive model of posttraumatic stress disorder. Behaviour Research and Therapy, 38, 319-345. doi:10.1016/S0005-7967(99)00123-0

Ehlers, A., Mayou, R.A., \& Bryant, B. (1998). Psychological predictors of chronic posttraumatic stress disorder after motor vehicle accidents. Journal of Abnormal Psychology, 107, 508-519. doi:10.1037/0021-843X.107.3.508

Ehring, T., Rank, S., \& Ehlers, A. (2008). The role of rumination and reduced concreteness in the maintenance of posttraumatic stress disorder and depression following trauma. Cognitive Therapy and Research, 32, 488-506. doi:10.1007/s10608-006-9089-7

Elhai, J.D., Carvalho, L.F., Miguel, F.K., Palmieri, P.A., Primi, R., \& Frueh, B.C. (2011). Testing whether posttraumatic stress disorder and major depressive disorder are similar or unique constructs. Journal of Anxiety Disorders, 25, 404-410. doi:10.1016/j.janxdis.2010.11.003

Elhai, J.D., Grubaugh, A.L., Kashdan, T.B., \& Frueh, C. (2008). Empirical examination of a proposed refinement to DSM-IV posttraumatic stress disorder symptom criteria using the National Comorbidity Survey Replication data. Journal of Clinical Psychiatry, 69, 597-602. doi:10.4088/JCP.v69n0411

Elkit, A., Armour, C., \& Shevlin, M. (2010). Testing alternative models of PTSD and the robustness of the dysphoria factor. Journal of Anxiety Disorders, 24, 147-154. doi:10.1016/j.janxdis.2009.10.002

Erickson, D.H., Janeck, A.S., \& Tallman, K. (2007). A cognitive behavioral group for patients with various anxiety disorders. Psychiatric Services, 58, 1205-1211. doi:10.1176/appl.ps.58.9.1205

Falsetti, S.A., Resnick, H.S., \& Davis, J. (2005). Multiple channel exposure therapy: Combining cognitive-behavioral therapies for the treatment of posttraumatic stress disorder with panic attacks. Behavior Modification, 29, 70-94. doi:10.1177/0145445504270874

Feeny, N.C., Zoellner, L.A., Fitzgibbons, L.A., \& Foa, E.B. (2000). Exploring the roles of emotional numbing, depression, and dissociation in PTSD. Journal of Traumatic Stress, 13, 489-498. doi:10.1023/A:1007789409330

Foa, E.B., \& Cahill, S.P. (2001). Psychological therapies: Emotional processing. In N.J. Smelser \& P.B. Bates (Eds.), International encyclopaedia of the social and behavioral sciences (pp. 12363-12369). Oxford, UK: Elsvier.

Foa, E.B., Dancu, C.V., Hembree, E.A., Jaycox, L.H., Meadows, E.A., \& Street, G.P. (1999a). A comparison of exposure therapy, stress inoculation training, and their combination for reducing posttraumatic stress disorder in female assault victims. Journal of Consulting and Clinical Psychology, 67, 194-200. doi:10.1037/0022-006X.67.2.194

Foa, E.B., Hembree, E.A., Cahill, S.P., Rauch, S.A.M., Riggs, D.S., Feeny, N.C., \& Yadin, E. (2005). Randomized trial of prolonged exposure for posttraumatic stress disorder with and without cognitive restructuring: Outcome at academic and community clinics. Journal of Consulting and Clinical Psychology, 73, 953-964. doi:10.1037/0022-006X.73.5.953 
Foa, E.B., Huppert, J.D., \& Cahil, S.P. (2006). Emotional processing theory: An update. In B.O. Rothbaum (Ed.), Pathological anxiety: Emotional processing in etiology and treatment (pp. 3-24). New York: Guilford Press.

Foa, E.B., \& Kozak, M.J. (1986). Emotional processing of fear: Exposure to corrective information. Psychological Bulletin, 99, 20-35. doi:10.1037/0033-2909.99.1.20

Foa, E.B., Riggs, D.S., Massie, E.D., \& Yarvzower, M. (1995). The impact of fear activation and anger on the efficacy of exposure treatment for posttraumatic stress disorder. Behavior Therapy, 26, 487-199. doi:10.1016/S0005-7894(05)80096-6

Forbes, D., Parslow, R., Creamer, M., O'Donnell, M., Bryant, R., McFarlane, A., ... Shalev, A. (2010). A longitudinal analysis of posttraumatic stress disorder symptoms and their relationship with fear and anxious-misery disorder: Implications for DSM-V. Journal of Affective Disorders, 127, 147-152. doi:10.1016/j.jad.2010.05.005

Ford, J.D., Elhai, J.D., Ruggiero, K.J., \& Frueh, B.C. (2009). Refining the posttraumatic stress disorder diagnosis: Evaluation of symptom criteria with the National Survey of Adolescents. Journal of Clinical Psychiatry, 70, 748-755. doi:10.4088/JCP.08m04692

Fu, Q., Koenen, K.C., Miller, M.W., Heath, A.C., Bucholz, K.K., Lyons, M.J., ... Tsuang, M.T. (2007). Differential etiology of posttraumatic stress disorder with conduct disorder and major depression in male veterans. Biological Psychiatry, 62, 1088-1094. doi:10.1016.j.biopsych.2007.04.036

Garnefski, N., Kraaij, V., \& Spinhoven, P. (2001). Negative life events, cognitive emotion regulation, and emotional problems. Personality and Individual Differences, 30, 1311-1327. doi:10.1016/S0191-8869(00)00113-6

Garnefski, N., Van Den Kommer, T., Kraaij, V., Teerds, J., Legerstee, J., \& Onstein, E. (2002). The relationship between cognitive emotion regulation strategies and emotional problems: Comparison between a clinical and non-clinical sample. European Journal of Personality, 16, 403-420. doi: $10.1002 /$ per.458

Gillespie, K., Duffy, M., Hackmann, A., \& Clark, D.M. (2002). Community-based cognitive therapy in the treatment of post-traumatic stress disorder following the Omagh bomb. Behaviour Research and Therapy, 40, 345-357. doi:10.1016/S0005-7967(02)00004-9

Goldman, R.N., \& Greenberg, L.S. (2005). Depth of emotional experience and outcome. Psychotherapy Research, 15, 248-260. doi:10.1080/10503300512331385188

Gonzalo, D., Kleim, B., Donaldson, C., Moorey, S., \& Ehlers, A. (2012). How disorderspecific are depressive attributions? A comparison of individuals with depression, posttraumatic stress disorder and healthy controls. Cognitive Therapy and Research, 36, 731-739. doi:10.1007/s10608-011-9429-0

Gotlib, I.H., \& Joormann, J. (2010). Cognition and depression: Current status and future directions. Annual Review of Clinical Psychology, 6, 285-312. doi:10.1146/annurev.clinpsy.121208.131305

Green, B.L., Krupnick, J.L., Chung, J., Siddique, J., Krause, E.D., Revicki, D., ... Miranda, J. (2006). Impact of PTSD comorbidity on one-year outcomes in a depression trial. Journal of Clinical Psychology, 62, 815-835. doi:10.1002/jclp.20279

Greenberg, L.S. (2002a). Emotion-focused therapy: Coaching clients to work through their feelings. Washington, DC: American Psychological Association.

Greenberg, L.S. (2002b). Integrating an emotion-focused approach to treatment in psychotherapy integration. Journal of Psychotherapy Integration, 12, 154-189. doi:10.1037/1053-0479.12.2.154

Greenberg, L.S., \& Pascual-Leone, A. (2006). Emotion in psychotherapy: A practice-friendly research review. Journal of Clinical Psychology, 62, 611-630. doi:10.1002/jclp.20252

Grubaugh, A.L., Long, M.E., Elhai, J.D., Frueh, B.C., \& Magruder, K.M. (2010). An examination of the construct validity of posttraumatic stress disorder with veterans using a revised criterion set. Behaviour Research and Therapy, 48, 909-914. doi:10.1016/j.brat.2010.05.019

Haaga, D.A.F., Dyck, M.J., \& Ernst, D. (1991). Empirical status of cognitive theory of depression. Psychological Bulletin, 110, 215-236. doi:10.1037/0033-2909.110.2.215 
Hamilton, K.E., \& Dobson, K.S. (2002). Cognitive therapy of depression: Pretreatment patient predictors of outcome. Clinical Psychology Review, 22, 875-893. doi:10.1016/S0272-7358(02)00106-X

Harvey, A.G., Bryant, R.A., \& Dang, S.T. (1998). Autobiographical memory in acute stress disorder. Journal of Consulting and Clinical Psychology, 66, 500-506. doi:10.1037/0022-006X.66.3.500

Hayes, S.C., Wilson, K.G., Gifford, E.V., Follette, V.M., \& Strosahl, K. (1996). Experiential avoidance and behavioral disorders: A functional dimensional approach to diagnosis and treatment. Journal of Consulting and Clinical Psychology, 64, 1152-1168. doi:10.1037/0022-006X.64.6.1152

Hein, D.A., Cohen, L.R., Miele, G.M., Litt, L.C., \& Capstick, C. (2004). Promising treatments for women with comorbid PTSD and substance use disorders. American Journal of Psychiatry, 161, 1426-1432. doi:10.1176/appi.161.8.1426

Hein, D.A., Wells, E.A., \& Nunes, E.V. (2009). Multi-site randomized trial of behavioral interventions for women with co-occurring PTSD and substance use disorders. Journal of Consulting and Clinical Psychology, 77, 607-619. doi:10.1037/a0016227

Hollon, S.D., Shelton, R.C., \& Davis, D.D. (1993). Cognitive therapy for depression: Conceptual issues and clinical efficacy. Journal of Consulting and Clinical Psychology, 61, 270-275. doi: $10.1037 / 0022-006 X .61 .2 .270$

Jakupcak, M., Roberts, L.J., Martell, C., Mulick, P., Michael, S., Reed, R., ... McFall, M. (2006). A pilot study of behavioral activation for veterans with posttraumatic stress disorder. Journal of Traumatic Stress, 19, 387-391. doi:10.1002/jys.20125

Jakupcak, M., Wagner, A., Paulson, A., Varra, A., \& McFall, M. (2010). Behavioral activation as a primary care-based treatment for PTSD and depression among returning veterans. Journal of Traumatic Stress, 23, 491-495. doi:10.1002/jts.20543

Jaycox, L.H., \& Foa, E.B. (1996). Obstacles in implementing exposure therapy for PTSD: Case discussions and practice solutions. Clinical Psychology and Psychotherapy, 3, 176-184. doi:10.1002/(SICI)1099-0879(199609)

Jaycox, L.H., Foa, E.B., \& Morral, A.R. (1998). Influence of emotional engagement and habituation on exposure therapy for PTSD. Journal of Consulting and Clinical Psychology, 66, 185-192. doi: $10.1037 / 0022-006$ X.66.1.185

Joormann, J., \& D'Avanzato, C. (2010). Emotion regulation in depression: Examining the role of cognitive processes. Cognition and Emotion, 24, 913-939. doi:10.1080/02699931003784939

Joormann, J., \& Gotlib, I.H. (2010). Emotion regulation in depression: Relation to cognitive inhibition. Cognition and Emotion, 24, 281-298. doi:10.1080/02699930903407948

Kahn, J.H., \& Garrison, A.M. (2009). Emotional self-disclosure and emotional avoidance: Relations with symptoms of depression and anxiety. Journal of Counselling Psychology, 56, 573-584. doi: $10.1037 / a 0016574$

Kessler, R.C., Berglund, P., Demler, O., Jin, R., Merikangas, K.R., \& Walters, E.E. (2005). Lifetime prevalence and age-of-onset distributions of DSM-IV disorders in the national comorbidity survey replication. Archives of General Psychiatry, 62, 593-602. doi:10.1001/archpsyc.62.6.593

Kessler, R.C., Chiu, W.T., Demler, O., \& Walters, E.E. (2005). Prevalence, severity, and comorbidity of 12-month DSM-IV disorders in the national comorbidity survey replication. Archives of General Psychiatry, 62, 617-627. doi:10.1001/archpsyc.62.6.617

Kessler, R.C., Sonnega, A., Bromet, E., \& Nelson, C.B. (1995). Posttraumatic stress disorder in the national comorbidity survey. Archives of General Psychiatry, 52, 1048-1060. doi:10.1001/archpsyc. 1995.03950240066012

Kilpatrick, D.G., Koenen, K.C., Ruggiero, K.J., Acierno, R., Galea, S., Resnick, H.S., . . Gelemter, J. (2007). The serotonin transporter genotype and social support and moderation of posttraumatic stress disorder and depression in hurricane-exposed adults. The American Journal of Psychiatry, 164, 1693-1699. doi:10.1176/appi.ajp.2007.06122007

Kleim, B., \& Ehlers, A. (2008). Reduced autobiographical memory specificity predicts depression and posttraumatic stress disorder after recent trauma. Journal of Consulting and Clinical Psychology, 76, 231-242. doi:10.1037/0022-006X.76.2.231 
Koenen, K.C., Fu, Q. J, Ertel, K., Lyons, M.J., Eisen, S.A., True, W.R., ... Tsuang, M.T. (2008). Common genetic liability to major depression and posttraumatic stress disorder in men. Journal of Affective Disorders, 105, 109-115. doi:10.1016/j.jad.2007.04.021

Koenen, K.C., Harley, R., Lyons, M.J., Wolfe, J., Simpson, J.C., Goldberg, J., ... Tsuang, M.T. (2002). A twin registry study of familial and individual risk factors for trauma exposure and posttraumatic stress disorder. Journal of Nervous and Mental Disease, 190, 209-218. doi:10.1097/00005053-200204000-00001

Kuyken, W., \& Dalgleish, T. (1995). Autobiographical memory and depression. British Journal of Clinical Psychology, 34, 89-92. doi:10.1111/j.2044-8260.1995.tb01441.x

Lee, H., Lee, M., Kang, R., Kim, H., Kim, S., Kee, B., .. Palk, I.H. (2005). Influence of the serotonin transporter promoter gene polymorphism on susceptibility to posttraumatic stress disorder. Depression and Anxiety, 21, 135-139. doi:10.1002/da.20064

Lemke, M.R., Puhl, P., \& Winkler, K.T. (1999). Psychomotor retardation and anhedonia in depression. Acta Psychiatric Scandinavica, 99, 252-256. doi:10.1111/j.1600-0447.1999.tb07221.x

Levens, S.M., Muhtadie, L., \& Gotlib, I.H. (2009). Rumination and impaired resource allocation in depression. Journal of Abnormal Psychology, 118, 757-766. doi:10.1037/a0017206

Liverant, G.I., Suvak, M.K., Pineles, S.L., \& Resick, P.A. (2012). Changes in posttraumatic stress disorder and depressive symptoms during cognitive processing therapy: Evidence for concurrent change. Journal of Consulting and Clinical Psychology, 80, 957-967. doi:10.1037/a0030485

Loas, G., Salinas, E., Guelfi, J.D., \& Samuel-Lajeunesse, B. (1992). Physical anhedonia in major depressive disorder. Journal of Affective Disorders, 25, 139-146. doi:10.1016/0165-0327(92)90076-I

Mansell, W., Carey, T.A., \& Tai, S.J. (2013). A transdiagnostic approach to CBT using method of levels therapy. Distinctive features. London: Routledge Taylor \& Frandis Group.

Marshall, G.N., Schell, T.L., Glynn, S.M., \& Shetty, V. (2006). The role of hyperarousal in the manifestation of posttraumatic psychological distress following injury. Journal of Abnormal Psychology, 115, 624-628. doi:10.1037/0021-843X.115.3.624

Marshall, G.N., Schell, T.L., \& Miles, J.N.V. (2010). All PTSD symptoms are highly associated with general distress: Ramifications for the dysphoria symptom cluster. Journal of Abnormal Psychology, 119,126-135. doi:10.1037/a0018477

Martell, C.R., Addis, M.E., \& Jacobson, N.S. (2001). Depression in context: Strategies for guided action. New York: W.W. Norton.

McDonagh, A., Friedman, M., McHugo, G., Ford, J., Sengupta, A., Mueser, K., ... Descamps, M. (2005). Randomized trial of cognitive-behavioral therapy for posttraumatic stress disorder in adult female survivors of childhood sexual abuse. Journal of Consulting and Clinical Psychology, 73, 515-524. doi:10.1037/0022-006.73.3.515

McMakin, D.L., Olino, T.M., Porta, G., Dietz, L.J., Emslie, G., Clarke, G., .. Brent, D.A. (2012). Anhedonia predicts poorer recovery among youth with selective serotonin reuptake inhibitor treatment-resistant depression. Journal of the American Academy of Child and Adolescent Psychiatry, 51, 404-411. doi:10.1016/j.jaac.2012.01.011

McMillen, J.C., North, C.S., \& Smith, E.M. (2000). What parts of PTSD are normal: Intrusion, avoidance, or arousal? Data from the Northridge, California, earthquake. Journal of Traumatic Stress, 13, 57-75. doi:10.1023/A:1007768830246

Meene, A. (2005). Assessment of psychological adjustment after trauma (unpublished honours thesis). Flinders University, Adelaide, South Australia, Australia.

Michael, T., Halligan, S.L., Clark, D.M., \& Ehlers, A. (2007). Rumination in posttraumatic stress disorder. Depression and Anxiety, 24, 307-317. doi:10.1002/da.20228

Michl, L.C., McLaughlin, K.A., Shepherd, K., \& Nolen-Hoeksema, S. (2013). Rumination as a mechanism linking stressful life events to symptoms of depression and anxiety: Longitudinal evidence in early adolescents and adults. Journal of Abnormal Psychology, 122, 339-352. doi:10.1037/a0031994

Miller, M.W., Wolf, E.J., Harrington, K.M., Brown, T.A., Kaloupek, D.G., \& Keane, T.M. (2010). An evaluation of competing models for the structure of PTSD symptoms using external measures of comorbidity. Journal of Traumatic Stress, 23, 631-638. doi:10.10002/jts.20559 
Missirlian, T.M., Toukmanian, S.G., Warwar, S.H., \& Greenberg, L.S. (2005). Emotional arousal, client perceptual processing, and the working alliance in experiential psychotherapy for depression. Journal of Consulting and Clinical Psychology, 73, 861-871. doi:10.1037/0022-006X.73.5.861

Monson, C.M., Price, J.L., Rodriguez, B.F., Ripley, M.P., \& Warner, R.A. (2004). Emotional deficits in military-related PTSD: An investigation of content and process disturbances. Journal of Traumatic Stress, 17, 275-279. doi:10.1023/B:JOTS.0000029271.58494.05

Moses, E.B., \& Barlow, D.H. (2006). A new unified treatment approach for emotional disorders based on emotional science. Current Directions in Psychological Science, 15, 146-150. doi: $10.1111 / \mathrm{j} .0963-7214.2006 .00425 . x$

Moulds, M.L., Kandris, E., Starr, S., \& Wong, A.C.M. (2007). The relationship between rumination, avoidance and depression in a non-clinical sample. Behaviour Research and Therapy, 45, 251-161. doi:10.1016/j.brat.2006.03.003

Mulick, P.S., \& Naugle, A.E. (2004). Behavioral activation for comorbid PTSD and major depression: A case study. Cognitive and Behavioural Practice, 11, 378-387. doi:10.1016/S1077-7229(04)80054-3

Najavits, L.M., Gallop, R.J., Weiss, R.D. (2006). Seeking Safety therapy for adolescent girls with PTSD and substance abuse: A randomized controlled trial. Journal of Behavioral Health Services and Research, 33, 453-463. doi:10.1007/s11414-006-9034-2

Najavits, L.M., Weiss, R.D., Shaw, S.R., \& Muenz, L.R. (1998). 'Seeking Safety': Outcome of a new cognitive-behavioral psychotherapy for women with posttraumatic stress disorder and substance dependence. Journal of Traumatic Stress, 11, 437-456. doi:10.1023/A:1024496427434

National Institute for Health and Clinical Excellence. (2005). Post-traumatic stress disorder (PTSD): The management of PTSD in adults and children in primary and secondary care. London: National Institute for Health and Clinical Excellence.

National Institute for Health and Clinical Excellence. (2009). Depression: The treatment and management of depression in adults. London: National Institute for Health and Clinical Excellence.

Nixon, R.D.V., Cain, N., Nehmy, T., \& Seymour, M. (2009). The influence of thought suppression and cognitive load on intrusions and memory processes following an analogue stressor. Behavior Therapy, 40, 368-379, doi:10.1016/j.beth.2008.10.004

Nixon, R.D.V., \& Nearmy, D.M. (2011). Treatment of comorbid posttraumatic stress disorder and major depressive disorder: A pilot study. Journal of Traumatic Stress, 24, 541-455. doi: $10.1002 /$ jts.20654

Nixon, R.D.V., Resick, P.A., \& Nishith, P. (2004). An exploration of comorbid depression among female victims of intimate partner violence with posttraumatic stress disorder. Journal of Affective Disorders, 82, 315-320. doi:10.1016/j.jad.2004.01.008

Nolen-Hoeksema, S. (2000). The role of rumination in depressive disorders and mixed anxiety/depressive symptoms. Journal of Abnormal Psychology, 109, 504-511. doi:10.1037/0021-843X.109.3.504

Nolen-Hoeksema, S., \& Morrow, J. (1991). A prospective study of depression and posttraumatic stress symptoms after a natural disaster: The 1989 Loma Prieta earthquake. Journal of Personality and Social Psychology, 61, 115-121. doi:10.1037/0022-3514.61.1.115

Norton, P.J., \& Philipp, L.M. (2008). Transdiagnostic approaches to the treatment of anxiety disorders: A quantitative review. Psychotherapy, Theory, Research, Practice, Training, 45, 214-226. doi: $10.1037 / 0033-3204.45 .2 .214$

Nunn, J.D., Mathews, A., \& Trower, P. (1997). Selective processing of concern related information in depression. British Journal of Clinical Psychology, 36, 489-503. doi:10.1111/j.2044-8260.1997.tb01256.x

O’Donnell, M.L., Creamer, M., \& Pattison, P. (2004). Posttraumatic stress disorder and depression following trauma: Understanding comorbidity. American Journal of Psychiatry, 161, 1390-1396. doi:10.1176/appi.ajp.161.8.1390

Paelecke-Habermann, Y., Pohl, J., \& Leplow, B. (2005). Attention and executive functions in remitted major depression patients. Journal of Affective Disorders, 89, 125-135. doi:10.1016/j.jad.2005.09.006 
Pascual-Leone, A., \& Greenberg, L. (2007). Emotional processing in experiential therapy: Why 'the only way out is through.' Journal of Consulting and Clinical Psychology, 75, 875-887. doi:10.1037/0022-006X.75.6.875

Poss, A.E., Greenberg, L.S., Goldman, R.N., \& Korman, L.M. (2003). Emotional processing during experiential treatment of depression. Journal of Consulting and Clinical Psychology, 71, 1007-1016. doi:10.1037/0022-006X.71.6.1007

Post, L.M., Zoellner, L.A., Youngstrom, E., \& Feeny, N.C. (2011). Understanding the relationship between co-occurring PTSD and MDD: Symptom severity and affect. Journal of Anxiety Disorders, 25, 1123-1130. doi:10.1016/j.janxdis.2011.08.003

Rauch, S.A.M., \& Foa, E.B. (2006). Emotional processing theory (EPT) and exposure therapy for PTSD. Journal of Contemporary Psychotherapy, 36, 61-65. doi:10.1007/s10879-006-9008-y

Resick, P.A., Galovski, T.E., Uhlmansiek, M.O., Scher, C.D., Clum, G.A., \& Young-Xu, Y. (2008). A randomized clinical trial to dismantle components of cognitive processing therapy for posttraumatic stress disorder in female victims of interpersonal violence. Journal of Consulting and Clinical Psychology, 76, 243-258. doi:10.1037/0022-006X.76.2.243

Resick, P.A., Nishith, P., Weaver, T.L., Astin, M.C., \& Feuer, C.A. (2002). A comparison of cognitive-processing therapy with prolonged exposure and a waiting condition for the treatment of chronic posttraumatic stress disorder in female rape victims. Journal of Consulting and Clinical Psychology, 70, 867-879. doi:10.1037/0022-006X.70.4.867

Resick, P.A., \& Schnicke, M.K. (1992). Cognitive processing therapy for sexual assault victims. Journal of Consulting and Clinical Psychology, 60, 748-756. doi:10.1037/0022-006X.60.5.748

Richards, J.M., \& Gross, J.J. (1999). Composure at any cost? The cognitive consequences of emotion suppression. Personality and Social Psychology Bulletin, 25, 1033-1044. doi: $10.1177 / 01461672992511010$

Rufer, M., Hand, I., Braatz, A., Alsleben, H., Fricke, S., \& Peter, H. (2004). A prospective study of alexithymia in obsessive-compulsive patients treated with multimodal cognitive-behavioral therapy. Psychotherapy and Psychosomatics, 73, 101-106. doi:10.1159/000075541

Salters-Pedneault, K., Tull, M.T., \& Roemer, L. (2004). The role of avoidance of emotional material in the anxiety disorders. Applied and Preventative Psychology, 11, 95-114. doi:10.1016/j.appsy.2004.09.001

Schell, T.L., Marshall, G.N., \& Jaycox, L.H. (2004). All symptoms are not created equal: The prominent role of hyperarousal in the natural course of posttraumatic psychological distress. Journal of Abnormal Psychology, 113, 189-197. doi:10.1037/0021-843X.113.2.189

Schottenbauer, M.A., Glass, C.R., Arnkoff, D.B., Tendick, V., \& Gray, S.H. (2008). Nonresponse and dropout rates in outcome studies on PTSD: Review and methodological considerations. Psychiatry, 71, 134-168. doi:10.1521/psyc.2008.71.2.134

Schulte, D., Künzel, R., Pepping, G., \& Schulte-Bahrenberg, T. (1992). Tailor-made versus standardized therapy of phobic patients. Advances in Behaviour Research $\mathcal{E}$ Therapy, 14, 67-92. doi:10.1016/0146-6402(92)90001-5

Seligman, M.E., Abramson, L.Y., Semmel, A., \& von Baeyer, C. (1979). Depressive attributional style. Journal of Abnormal Psychology, 88, 242-247. doi:10.1037/0021-843X.88.3.242

Shalev, A.Y., Freedman, S., Peri, T., Brandes, D., Sahar, T., Orr, S.P., \& Pitman, R.K. (1998). Prospective study of posttraumatic stress disorder and depression following trauma. The American Journal of Psychiatry, 155, 630-637. Retrieved from http://ajp.psychiatryonline. org/data/Journals/AJP/3688/630.pdf

Sloan, D.M., \& Kring, A.M. (2007). Measuring changes in emotion during psychotherapy: Conceptual and methodological issues. Clinical Psychology: Science and Practice, 14, 307-322. doi: $10.1111 / j .1468-2850.2007 .00092 . x$

Smith, J., \& Alloy, L. (2009). A roadmap to rumination: A review of the definition, assessment, and conceptualization of this multifaceted construct. Clinical Psychology Review, 29, 116-128. doi:10.1016/j.cpr.2008.10.003 
Stander, V.A., Thomsen, C.J., \& Highfill-McRoy, R.M. (2014). Etiology of depression comorbidity in combat-related PTSD: A review of the literature. Clinical Psychology Review, 34, 87-98. doi:10.1016/j.cpr.2013.12.002

Stein, N.R., Dickstein, B.D., Schuster, J., Litz, B.T., \& Resick, P.A. (2012). Trajectories of response to treatment for posttraumatic stress disorder. Behavior Therapy, 43, 790-800. doi:10.1016/j.beth.2012.04.003

Stringer, J.V., Levitt, H.M., Berman, J.S., \& Mathews, S.S. (2010). A study of silent disengagement. Psychotherapy Research, 20, 495-510. doi:10.1080/10503301003754515

Sullivan, P.F., Neale, M.C., \& Kendler, K.S. (2000). Genetic epidemiology of major depression: Review and meta-analysis. The American Journal of Psychiatry, 157, 1552-1562. doi:10.1176/appi.ajp.157.10.1552

Summer, J.A., Griffith, J.W., \& Mineka, S. (2010). Overgeneral autobiographical memory as a predictor of the course of depression: A meta-analysis. Behaviour Research and Therapy, 48, 614625. doi:10.1016/j.brat.2010.03.013

Suveg, C., Southam-Gerow, M.A., Goodman, K.L., \& Kendall, P.C. (2007). The role of emotion theory and research in child therapy development. Clinical Psychology: Science and Practice, 14, 358-371. doi:10.1111/j.1468-2850.2007.00096.x

Taylor, S., Fedoroff, I.C., Koch, W.J., Thordarson, D.S., Fecteau, G., \& Nicki, R.M. (2001). Posttraumatic stress disorder arising after road traffic collisions: Patterns of response to cognitive-behavior therapy. Journal of Consulting and Clinical Psychology, 69, 541-551. doi:10.1037/0022-006X.69.3.541

True, W.R., Rice, J., Eisen, S.A., Heath, A.C., Goldberg, J., Lyon, M.J., \& Nowak, J. (1993). A twin study of genetic and environmental contributions to liability for posttraumatic stress symptoms. Archives of General Psychiatry, 50, 257-265. doi:10.1001/archpsyc

Viinamäki, H., Hintikka, J., Tanskanen, A., Honkalampi, K., Antikainen, R., Koivumaa-Honkanen, H., ... Lehtonen, J. (2002). Partial remission in major depression: A two-phase, 12-month prospective study. Nordic Journal of Psychiatry, 56, 33-37. doi:10.1080/08039480252803891

Wagner, A.W., Zatzick, D.F., Ghesquiere, A., \& Jurkovich, G.J. (2007). Behavioral activation as an early intervention for posttraumatic stress disorder and depression among physically injured trauma survivors. Cognitive and Behavioral Practice, 14, 341-349. doi:10.1016/j.cbpra.2006.05.002

Wald, J., Taylor, S., Chiri, L.R., \& Sica, C. (2010). Posttraumatic stress disorder and chronic pain arising from motor vehicle accidents: efficacy of interoceptive exposure plus trauma-related exposure therapy. Cognitive Behaviour Therapy, 29, 104-113. doi:10.1080/16506070903183570

Wenzlaff, R.M., \& Wegner, D.M. (2000). Thought suppression. Annual Review of Psychology, 51, 59-91. doi:10.1146/annurev.psych.51.1.59

Williams, J.M.G., Barnhoefer, T., Crane, C., Hermans, D., Raes, F., Watkins, E., \& Dalgliesh, T. (2007). Autobiographical memory specificity and emotional disorder. Psychological Bulletin, 113, 122-148. doi:10.1037/0033-2909.133.1.122

Williams, J.M.G., \& Scott, J. (1988). Autobiographical memory in depression. Psychological Medicine, 18, 689-695. doi: $10.1017 /$ S0033291700008370

Zeman, J., Klimes-Dougan, B., Cassano, M., \& Adrian, M. (2007). Measurement issues in emotion research with children and adolescents. Clinical Psychology: Science and Practice, 14, 377-401. doi:10.1111/j.1468-2850.2007.00098.x

Zimering, R., Caddell, J.M., Fairbank, J.A., \& Keane, T.M. (1993). Post-traumatic stress disorder in Vietnam veterans: An experimental validation of the DSM-III diagnostic criteria. Journal of Traumatic Stress, 6, 327-342. doi:10.1002/jts.2490060304 